\title{
Neighborhood stressors and social support as predictors of depressive symptoms in the Chicago Community Adult Health Study
}

\author{
Christina Mair ${ }^{\text {a,b,c,**}, \text { Ana V. Diez Roux }}{ }^{\text {d,a,b, Jeffrey D. Morenoff }}{ }^{\text {ef,g }}$ \\ ${ }^{a}$ Center for Social Epidemiology and Population Health, University of Michigan, 3rd Floor SPH Tower, 109 S Observatory, Ann Arbor, MI 48109-2029, USA \\ ${ }^{\mathrm{b}}$ Department of Epidemiology, University of Michigan, 1415 Washington Heights, 4647 SPH Tower, Ann Arbor, MI 48109-2029, USA \\ c Prevention Research Center, 1995 University Avenue, Suite 450, Berkeley, CA 94704, USA \\ d Center for Integrative Approaches to Health Disparities, University of Michigan, 1415 Washington Heights, 3645 SPH Tower I and 4648 SPH Tower I Ann Arbor MI \\ 48109-2029, USA \\ e Department of Sociology, University of Michigan, Room 3001 LSA Building, 500 South State Ann Arbor, MI 48109-1382, USA \\ ${ }^{f}$ Population Studies Center, University of Michigan, 426 Thompson St Ann Arbor, MI 48106-1248, USA \\ ${ }^{\mathrm{g}}$ Survey Research Center, University of Michigan, 1355 ISR Building, P.O. Box 1248, Ann Arbor, MI 48106, USA
}

\section{A R T I C L E I N F O}

\section{Article history:}

Received 3 September 2009

Received in revised form 19 March 2010

Accepted 2 April 2010

Keywords:

Depression

Residence characteristics

Neighborhoods

Stressors

Social support

\begin{abstract}
A B S T R A C T
There is a growing interest in understanding the effects of specific neighborhood conditions on psychological wellbeing. We examined cross-sectional associations of neighborhood stressors (perceived violence and disorder, physical decay and disorder) and social support (residential stability, family structure, social cohesion, reciprocal exchange, social ties) with depressive symptoms in 3105 adults in Chicago. Subjects lived in 343 neighborhood clusters, areas of about two census tracts. Depressive symptoms were assessed with an 11-item version of the Center for Epidemiologic StudiesDepression (CES-D) scale. Neighborhood variables were measured using rater assessments, surveys, and the US census. We used two-level gender-stratified models to estimate associations of neighborhood conditions with depressive symptoms after adjusting for individual-level covariates. Most social support variables were associated with lower levels of depressive symptoms in women but not men, while stressors were moderately associated with higher levels in all subjects. Adjusting concurrently for stressors and social support did not change results. This suggests both neighborhood stressors and social support are associated with depressive symptoms.
\end{abstract}

(c) 2010 Elsevier Ltd. All rights reserved.

\section{Introduction}

Despite several recent studies linking depression and depressive symptoms to characteristics of residential neighborhoods, little is known about which features of neighborhoods pose the strongest risks for depression and whether neighborhood support structures might help reduce the incidence of depression (Mair et al., 2008). Both exposure to stressors and social support have been linked to the development of depressive symptoms and depression in individuals (Mulvaney and Kendrick, 2005; Latkin and Curry, 2003; Steptoe and Feldman, 2001; Schulz et al., 2006; Kubzansky et al., 2005; Fitzpatrick et al., 2005), but there is not as much prior research on neighborhood-level sources of stress or social support and how they are related to depression. Key among the limitations in the literature are the need to simultaneously

\footnotetext{
* Corresponding Author at: Prevention Research Center, 1995 University Avenue, Suite 450, Berkeley, CA 94704, USA, Tel.: 1510883 5762; fax: 15106440594.

E-mail addresses: cmair@prev.org (C. Mair), adiezrou@umich.edu (A.V. Diez Roux), morenoff@isr.umich.edu (J.D. Morenoff).
}

assess several dimensions of neighborhoods and the need to measure these dimensions in ways that minimize measurement error and avoid bias. Identifying which features of the neighborhood environment are associated with depressive symptoms is central to understanding the processes involved and therefore strengthening causal inferences regarding neighborhood effects on mental health.

A number of physical and social features of neighborhoods may operate as stressors. Physical aspects of neighborhoods, including the presence of vacant or abandoned buildings, the amount of litter and graffiti, and the presence of physical decay generally, may send visual cues that the neighborhood is not a safe or desirable place to live, which in turn can make residents view their neighborhood environment as more stressful (Kruger et al., 2007; Latkin and Curry, 2003; Lewis and Maxfield, 1980). The absence of green spaces may limit the stress-lowering effect of exposure to natural environments (Groenewegen et al., 2006). Perceptions of the neighborhood environment as unsafe, violent, or highly disordered can increase feelings of distress, both directly and indirectly, through increased feelings of powerlessness and fear (Perkins and Taylor, 1996; Ross and Jang, 2000). 
At the same time, neighborhoods provide social connections to people that may buffer the effects of stressors. For example, the density of social ties in a neighborhood and the level of reciprocal exchanges and social cohesion among neighbors may influence residents' feelings of safety and counteract the stressful cues in their neighborhood environments (Kubzansky et al., 2005; Aneshensel and Sucoff, 1996; Finfgeld-Connett, 2005). Other social structural features of neighborhoods such as family structure and residential stability may also affect the quality and quantity of social ties with possible implications for mental health (Sampson et al., 1997; Ross et al., 2000b, Matheson et al., 2006; Sampson, 1987).

We used data from the Chicago Community Adult Health Study (CCAHS), a population-based sample of adults age 18 and over in the city of Chicago with detailed measures of neighborhood social environments, to examine associations of various measures of neighborhood stressors and social connections/ support with depressive symptoms in residents. Our study advances prior work by using a variety of different approaches to construct neighborhood measures, including systematic social observation, surveys, and census data.

\section{Methods}

\subsection{Study setting and population}

Data came from the Chicago Community Adult Health Study (CCAHS), a stratified, multistage probability sample of 3105 adults living in Chicago, IL. This sample was drawn from 343 neighborhood clusters, defined through the Project on Human Development in Chicago Neighborhoods (PHDCN) (Sampson et al., 1997). Clusters typically consist of two census tracts, and have meaningful physical and social borders. One adult aged 18 or over was interviewed from each sampled home, with a final response rate of $72 \%$. Subjects were oversampled from 80 focal neighborhood clusters, defined by the PHDCN and chosen due to their socioeconomically and racially-ethnically heterogeneous composition. The sample had an average of 9.1 subjects per neighborhood cluster (range: 1-21). Neighborhood clusters were used as the primary neighborhood definition.

The sampling approach together with differential participation rates resulted in greater representation of women and African Americans, while men, whites and those making over $\$ 50,000 /$ year were underrepresented. Sample weights were therefore used in all data analyses to handle differential rates of selection and participation by neighborhood cluster and to make the results more generalizable to Chicago's population circa 2003. The sample weight was constructed as a multiplicative combination of three weights: one to adjust for oversampling of individuals in focal neighborhood clusters, one to adjust for whether a participant was selected for intensive non-response follow-up at the end of the survey, and one post-stratification weight (to make the age, sex, and racial/ethnic composition of the sample match that of the city of Chicago circa 2003). The weight was centered to have a mean of 1.0 (range: 0.2-5.4) (Morenoff et al., 2007).

\subsection{Data collection and variables}

The main outcome, subjects' depressive symptoms, was measured with an 11-item version of the Center for Epidemiologic Studies-Depression (CES-D) (Radloff, 1977) scale that has been validated in prior research (Kohout et al., 1993) and been shown to have good internal consistency and strong correlations with the original version of the CES-D (Carpenter et al., 1998). Each item in the shortened CES-D scale was scored from 1-4, with a higher score representing more depressive symptoms (Everson-Rose et al., 2004). The average score on the eleven questions was used in all analyses (range: 1-3.82).

Neighborhood-level variables were measured using rater assessments of the physical environment, surveys, and the 2000 US census. Rater-assessed measures of physical disorder and physical decay were obtained using systematic social observation (SSO), a method for making observations about neighborhoods in a systematic manner. Observations were collected from May 2001 to March 2003 (Sampson et al., 2007). Raters filled out a form for every block on which at least one study participant lived. A standard block includes four streets and eight street sides. The block-group-level scale reliability of the physical disorder (0.94) and physical decay (0.65) measures were quite high. Neighborhood-cluster-level measures for each scale was created using empirical Bayes estimation, which adjusts for missing items and improves neighborhood-level estimates by borrowing information across clusters (Mujahid et al., 2007). This was done by fitting an unconditional three-level hierarchical linear model for each scale, with item dummies predicting the scale score at level one and no predictors at levels two and three. The empirical Bayes level two residual from this model was added to the fitted value to produce the neighborhood cluster scale score. There were 6631 observations at the street level, with an average of 19.4 observations per neighborhood cluster. Physical disorder is a nine-item scale that captures the extent of graffiti, litter, abandoned cars, broken glass, and other similar types of negative neighborhood contamination (Sampson and Raudenbush, 1999). Physical decay is a five-item scale that describes the deterioration and abandonment of residential, commercial, and recreational buildings on a block.

Survey-based measures of perceived neighborhood disorder and violence (each has five items scored from 1-4), reciprocal exchange (four items, scored from 1-4), social ties (two items, scored from 1-5) and social cohesion (five items, scored from 1-4) were obtained from a survey administered to the 3105 CCHAS study participants. Each of these measures has been used in previous studies (Sampson et al., 1999; Morenoff, 2003). Neighborhood-cluster-level measures for each scale were created using empirical Bayes estimation in the same manner as described for the SSO variables.

We also constructed four scales from the 2000 census: disadvantage, affluence, family structure, and residential stability. Disadvantage was calculated as the mean of the following neighborhood- cluster-level variables (each standardized before averaging): the percentage of residents with annual incomes less than $\$ 10,000$, the percentage of residents with incomes greater than $\$ 50,000$ (reverse coded), the unemployment rate, the poverty rate, the percentage of unoccupied homes, and the public assistance rate. Affluence was calculated similarly from the following five variables: the percentage of residents with a Bachelor's degree and the percentage in professional/managerial occupation, the percentage of residence less than 18 years old and the median home value (for owner-occupied housing units). Census measures of family structure and residential stability were used as additional proxies for social connections. Residential stability consisted of two items: the percentage of residents in the same home for at least five years and the percent of owneroccupied housing units. Family structure also had two items: the percentage of female-headed households with children (reversecoded) and the percentage of people aged 15 and above who were married.

Because the multiple neighborhood variables we examined were often highly correlated and their associations with depression could not be reliably isolated from each other, we used 
factors analysis to derive summaries of the neighborhood variables. Our a priori assumption was that there would be two underlying constructs in the data, reflecting stressors (e.g. perceived disorder and violence, physical decay and disorder) and social cohesion/support-related variables. Since the censusbased measures were more distant proxies for these constructs than the SSO or survey measures, they were not included in the factor analysis. Factor analysis with orthogonal rotation was used with the remaining seven variables, and all factors with eigenvalues greater than one were retained, resulting in two factors: the first factor represented stressors, with high loadings for perceived disorder and violence, observed disorder and decay and (negative) social cohesion, while the second factor represented social support/cohesion, with high loadings for reciprocal exchange, social ties, and social cohesion. Social cohesion was the only variable that loaded onto both factors.

Additional covariates in the analysis included individual-level measures of age, gender, race/ethnicity, income, marital status and highest level of education achieved. Age was used as a continuous variable with a squared term to account for the nonlinearity of the age-depressive symptoms relationship. Race/ ethnicity categories included non-Hispanic white, non-Hispanic African American, non-Hispanic other, and Hispanic. Education was categorized into four groups (0-11 years, 12 years, 13-15 years, $16+$ years), and income was put into six categories (\$0-5000, \$5000-9999, \$10000-29999, \$30000-49999, $\geq \$ 50000$, and missing (18.8\%)). Marital status was categorized into five groups: married, separated, divorced, widowed, and never married. There were a few subjects missing individual-level covariate information ( 5 missing education, 3 missing marital status, 9 missing race/ethnicity). Case-by-case ("clinical") imputations were done for each missing value for these 3 variables.

\subsection{Data analysis}

All analyses were initially stratified by gender, as it has been found that neighborhood conditions impact men and women differently (Mair et al., 2009). Although none of the thirteen interactions between neighborhood factors and gender were statistically significant in final models, gender stratification was retained for comparability with other work. All neighborhood variables were transformed to z-scores in order to compare the relative strength of their associations with depressive symptoms. Unadjusted relationships between each of the neighborhood variables and depressive symptoms were examined (using scatter plots, lowess curves, and by estimating depressive symptom means for quartiles of each neighborhood variable and testing for a trend across categories) to see if there were substantial departures from linear relationships, but all appeared to be linear (or very close to linear).

We fit two-level multilevel models with a random intercept for each neighborhood to examine associations between neighborhood characteristics and depressive symptoms before and after adjusting for individual-level sociodemographic variables. Our modeling strategy was to insert each neighborhood variable oneat-a-time into models with (a) no covariates and (b) all of the individual-level covariates. The only exception to this strategy was that the two orthogonal factor scores-representing summary measures of stressors and social support-were inserted simultaneously into the models with and without individual-level covariates. Intraclass Correlation Coefficients (ICCs) were calculated for null models (no predictors), models with individual-level predictors only, and models with neighborhood-level covariates.

We examined the effects of neighborhood survey variables at both the neighborhood cluster (i.e. survey-based measures) and individual level (i.e. participant-reported measures). We ran models including each type of measure separately as well as simultaneously in the same model. All descriptive analyses were done with STATA version 9, and all of the random effects models were run using HLM version 6.06.

\section{Results}

Table 1 shows the weighted distribution of individual- and neighborhood-level covariates for the sample. The mean age was 42.5 years, $38 \%$ were white, $26 \%$ Hispanic, and 32\% Black. Approximately $44 \%$ of men and $39 \%$ of women were married, while $41 \%$ and $33 \%$ respectively had never married (Table 1 ). Twenty-eight percent of participants had 16 or more years of education, while $23 \%$ had fewer than 12 years. A greater percentage of men $(31 \%)$ than women $(22 \%)$ reported an annual income over $\$ 50,000$.

Table 2 shows mean CES-D scores for men and women, with each neighborhood characteristic used both as quartiles and as a continuous variable. The three types of neighborhood variables (SSO, survey, and census-based) were related to CES-D scores in the expected direction. Subjects living in neighborhoods with less physical disorder and decay, lower perceived violence and disorder, greater reciprocal exchange and social cohesion, greater proportions of married couples/fewer single mothers, and more residential stability had lower levels of depressive symptoms. No associations were observed for social ties. With the exception of social ties, all other quartiles of neighborhood-level variables showed statistically significant graded dose-repose relationships with depression among women (from a test for trend), but among men only physical decay, perceived disorder, social cohesion, and family structure did. Continuous neighborhood variables showed similar patterns as the neighborhood quartiles, with 14 of the 18 statistical tests for continuous predictors in OLS regression reaching statistical significance $(p<0.05)$ (Table 2$)$.

Table 3 shows the mean difference in depressive symptoms per one standard deviation increase in each neighborhood variable, both without and with adjustment for individual-level covariates, in separate models for each neighborhood covariate. The ICCs for null models (no predictors) at the neighborhood cluster level were $7.1 \%$ and $7.4 \%$ for women and men, respectively. These were reduced by about half when controlling for individuallevel covariates (education, income, age and marital status), to $3.9 \%$ (women) and 3.3\% (men). The ICCs for models with only neighborhood-level variables ranged from $4.3 \%$ to $7.1 \%$ for women and $4.0 \%$ to $7.5 \%$ for men at the neighborhood cluster level. Controlling for individual-level covariates reduced the ICCs to ranges of $3.0-4.0 \%$ (women) and $2.8-3.6 \%$ (men).

All of the stressor variables-observed and perceived disorder, physical decay, and perceived violence-were positively and significantly associated with CES-D scores among both men and women before adjusting for individual-level factors (Table 3). After adjusting for individual-level factors, however, only perceived violence remained significantly associated with CES-D for both men and women, although perceived disorder was also associated with CES-D scores amongst men. None of the raterassessed (SSO) neighborhood stressors were significantly associated with CES-D after adjusting for individual-level factors.

The relationships among the social support variables and depressive symptoms varied more by gender (Table 3 ). Among women, social cohesion, reciprocal exchange, residential stability, and neighborhood family structures with more married couples and fewer single mothers were all negatively and significantly associated with CES-D scores even after adjusting for 
Table 1

Selected individual- and neighborhood-level characteristics of CCAHS study participants, by gender.

\begin{tabular}{|c|c|c|c|}
\hline & All Participants $(n=3105)$ & Men $(n=1235)$ & Women $(n=1870)$ \\
\hline \multicolumn{4}{|l|}{ Individual-Level Characteristics } \\
\hline Age (years) ${ }^{a}$ & $42.5(0.42)$ & $41.5(0.58)$ & $43.4(0.51)$ \\
\hline \multicolumn{4}{|l|}{ Race/Ethnicity (\% distribution) } \\
\hline Hispanic & 25.8 & 26.5 & 25.2 \\
\hline Non-Hispanic White & 38.4 & 40.2 & 36.7 \\
\hline Non-Hispanic Black & 32.1 & 28.8 & 35.0 \\
\hline Other & 3.8 & 4.5 & 3.1 \\
\hline \multicolumn{4}{|l|}{ Marital Status (\% distribution) } \\
\hline Married & 41.8 & 44.5 & 39.4 \\
\hline Separated & 4.0 & 3.3 & 4.7 \\
\hline Divorced & 10.8 & 9.0 & 12.4 \\
\hline Widowed & 6.7 & 2.8 & 10.3 \\
\hline Never Married & 36.7 & 40.6 & 33.3 \\
\hline \multicolumn{4}{|c|}{ Annual Income (dollars) (\% distribution) } \\
\hline$<5000$ & 3.0 & 3.0 & 3.0 \\
\hline 5000-9999 & 7.1 & 6.2 & 7.9 \\
\hline $10,000-29,999$ & 26.2 & 23.6 & 28.5 \\
\hline $30,000-49,999$ & 18.4 & 19.3 & 17.6 \\
\hline $50,000+$ & 26.5 & 31.3 & 22.1 \\
\hline Missing & 18.8 & 16.5 & 20.8 \\
\hline \multicolumn{4}{|c|}{ Education (years) (\% distribution) } \\
\hline$<12$ & 23.4 & 22.4 & 24.4 \\
\hline 12 & 23.8 & 24.8 & 22.8 \\
\hline $13-15$ & 24.9 & 23.6 & 26.1 \\
\hline $16+$ & 27.9 & 29.3 & 26.7 \\
\hline \multicolumn{4}{|c|}{ Neighborhood-Level Characteristics } \\
\hline Physical Disorder ${ }^{\mathrm{a}}$ & $-2.09(0.09)$ & $-2.15(0.10)$ & $-2.03(0.09)$ \\
\hline Physical Decay ${ }^{a}$ & $-3.27(0.04)$ & $-3.29(0.05)$ & $-3.25(0.05)$ \\
\hline Perceived Violence ${ }^{a}$ & $1.83(0.01)$ & $1.82(0.02)$ & $1.84(0.01)$ \\
\hline Perceived Disorder ${ }^{\mathrm{a}}$ & $2.49(0.02)$ & $2.48(0.03)$ & $2.49(0.02)$ \\
\hline Social Ties in Neighborhood ${ }^{a}$ & $2.63(0.01)$ & $2.63(0.01)$ & $2.63(0.01)$ \\
\hline Reciprocal Exchange $^{a}$ & $2.86(0.01)$ & $2.86(0.01)$ & $2.86(0.01)$ \\
\hline Social Cohesion $^{\mathrm{a}}$ & $3.05(0.01)$ & $3.05(0.01)$ & $3.05(0.01)$ \\
\hline Family Structure ${ }^{\mathrm{a}, \mathrm{b}}$ & $0.18(0.05)$ & $0.22(0.05)$ & $0.15(0.05)$ \\
\hline Residential Stability $^{a}$ & $-0.05(0.06)$ & $-0.11(0.07)$ & $0.01(0.06)$ \\
\hline Disadvantage $^{a}$ & $-0.24(0.04)$ & $-0.29(0.05)$ & $-0.19(0.04)$ \\
\hline Affluence $^{\mathrm{a}}$ & $0.24(0.07)$ & $0.31(0.09)$ & $0.17(0.07)$ \\
\hline
\end{tabular}

${ }^{\text {a }}$ Mean(standard error).

${ }^{\mathrm{b}}$ Family structure $=\%$ female-headed households with children (reverse-coded) and \% married people aged $15+$.

individual-level factors. Among men, social cohesion, residential stability, and neighborhood family structure were all significantly associated with CES-D scores before adjusting for individual-level factors, but only the family structure variable remained a significant predictor after adjustment. The measure of neighborhood social ties was not associated with CES-D scores in any of the models.

Table 3 also shows the mean difference in depressive symptoms per one unit increase in the two neighborhood summary factors (stressors and social support/cohesion) adjusted for each other. In this model, the neighborhood stressor factor was positively associated with depressive symptoms in both men and women, although this association only remained significant among women after adjusting for individual-level covariates. The social support factor was significantly associated with depressive symptoms among women even after adjusting for individual-level covariates, but there was no significant association among men. Supplemental analysis (data not shown) revealed that after further adjusting for measures of neighborhood disadvantage and affluence (constructed from census data), the neighborhood stressor and social support factors were each still significantly associated with depressive symptoms among women.

Table 4 shows associations between depressive symptoms and survey variables (social cohesion, reciprocal exchange, perceived violence, perceived disorder, social ties), using each variable at the participant-level, neighborhood cluster-level, and both levels simultaneously. Correlations between individual-level social support and corresponding neighborhood cluster-level social support variables were relatively low $(0.38-0.44)$. The correlations between individual and neighborhood measures of violence and disorder were slightly higher (0.64 and 0.53 , respectively). Associations between depressive symptoms and both perceived violence and perceived disorder were stronger using the individual-level measures of the perceptions than with the neighborhood-level measures. In the model that included measures from both levels, only the individual-level measures remained significantly and positively associated with depression. The significant associations between measures of social support (social cohesion, reciprocal exchange, social ties) and depressive symptoms were generally of similar magnitude when using either individual- or neighborhood-level measures separately, but when both were introduced into the same model, only the individuallevel measures (for social cohesion in men and women and for social ties in men) remained associated with depressive symptoms (Table 4 )

\section{Discussion}

Neighborhood stressors and social support were cross-sectionally associated with depressive symptoms in this population of 
Table 2

Mean Center for Epidemiologic Studies-Depression (CES-D) score (95\% confidence interval) by neighborhood characteristics $(n=3105)$.

\begin{tabular}{|c|c|c|c|}
\hline Neighborhood Characteristic & Quartile & Mean CES-D Score: Men $(n=1235)$ & Mean CES-D Score: Women $(n=1870)$ \\
\hline \multicolumn{4}{|l|}{ STRESSORS } \\
\hline \multirow[t]{6}{*}{ Physical Disorder (SSO) } & 1st (most favorable) & $1.72(1.65,1.80)$ & $1.77(1.70,1.84)$ \\
\hline & 2nd & $1.71(1.61,1.82)$ & $1.83(1.73,1.92)$ \\
\hline & $3 r d$ & $1.75(1.65,1.85)$ & $1.94(1.84,2.03)$ \\
\hline & 4 th & $1.82(1.71,1.93)$ & $1.96(1.87,2.05)$ \\
\hline & $p$-value ${ }^{a}$ & 0.24 & $<0.01$ \\
\hline & continuous ( $p$-value $)^{\mathrm{a}}$ & $0.04(0.05)$ & $0.08(<0.01)$ \\
\hline \multirow[t]{6}{*}{ Physical Decay (SSO) } & 1st (most favorable) & $1.76(1.69,1.83)$ & $1.85(1.79,1.92)$ \\
\hline & 2nd & $1.64(1.54,1.74)$ & $1.77(1.68,1.87)$ \\
\hline & 3rd & $1.74(1.64,1.84)$ & $1.92(1.82,2.01)$ \\
\hline & 4 th & $1.87(1.76,1.97)$ & $1.96(1.87,2.05)$ \\
\hline & $p$-value & $<0.01$ & $<0.01$ \\
\hline & continuous ( $p$-value) & $0.05(0.02)$ & $0.06(<0.01)$ \\
\hline \multirow[t]{6}{*}{ Perceived Violence } & 1st (most favorable) & $1.70(1.63,1.78)$ & $1.74(1.67,1.81)$ \\
\hline & 2nd & $1.71(1.61,1.82)$ & $1.85(1.76,1.95)$ \\
\hline & 3rd & $1.74(1.63,1.85)$ & $1.91(1.82,2.01)$ \\
\hline & 4th & $1.85(1.74,1.95)$ & $1.98(1.89,2.07)$ \\
\hline & $p$-value & 0.02 & $<0.01$ \\
\hline & continuous ( $p$-value) & $0.08(<0.01)$ & $0.10(<0.01)$ \\
\hline \multirow[t]{6}{*}{ Perceived Disorder } & 1st (most favorable) & $1.66(1.59,1.74)$ & $1.72(1.65,1.79)$ \\
\hline & 2nd & $1.77(1.66,1.89)$ & $1.90(1.80,2.00)$ \\
\hline & $3 r d$ & $1.70(1.60,1.80)$ & $1.91(1.82,2.01)$ \\
\hline & 4 th & $1.87(1.76,1.97)$ & $1.98(1.89,2.07)$ \\
\hline & $p$-value & $<0.01$ & $<0.01$ \\
\hline & continuous ( $p$-value) & $0.07(<0.01)$ & $0.10(<0.01)$ \\
\hline \multicolumn{4}{|l|}{ SOCIAL SUPPORT } \\
\hline \multirow[t]{6}{*}{ Social Cohesion } & 1st (least favorable) & $1.86(1.79,1.93)$ & $1.99(1.94,2.05)$ \\
\hline & 2nd & $1.78(1.68,1.89)$ & $1.88(1.80,1.97)$ \\
\hline & $3 r d$ & $1.65(1.55,1.75)$ & $1.87(1.78,1.96)$ \\
\hline & 4 th & $1.71(1.61,1.81)$ & $1.75(1.67,1.84)$ \\
\hline & $p$-value & $<0.01$ & $<0.01$ \\
\hline & continuous ( $p$-value) & $-0.06(<0.01)$ & $-0.09(<0.01)$ \\
\hline \multirow[t]{6}{*}{ Reciprocal Exchange } & 1st (least favorable) & $1.77(1.71,1.84)$ & $1.90(1.84,1.97)$ \\
\hline & 2nd & $1.78(1.68,1.89)$ & $1.96(1.87,2.05)$ \\
\hline & 3rd & $1.74(1.64,1.85)$ & $1.84(1.75,1.93)$ \\
\hline & 4 th & $1.70(1.60,1.79)$ & $1.80(1.71,1.89)$ \\
\hline & $p$-value & 0.31 & 0.01 \\
\hline & continuous ( $p$-value) & $-0.02(0.17)$ & $-0.05(<0.01)$ \\
\hline \multirow[t]{6}{*}{ Social Ties } & 1st (least favorable) & $1.75(1.69,1.82)$ & $1.95(1.89,2.00)$ \\
\hline & 2 nd & $1.78(1.68,1.88)$ & $1.84(1.75,1.93)$ \\
\hline & $3 r d$ & $1.73(1.63,1.83)$ & $1.85(1.76,1.93)$ \\
\hline & 4 th & $1.73(1.64,1.83)$ & $1.86(1.78,1.95)$ \\
\hline & $p$-value & 0.78 & 0.06 \\
\hline & continuous ( $p$-value) & $-0.01(0.65)$ & $-0.02(0.23)$ \\
\hline \multirow[t]{6}{*}{ Residential Stability } & 1st (least stable) & $1.79(1.71,1.86)$ & $1.94(1.87,2.01)$ \\
\hline & 2nd & $1.80(1.69,1.90)$ & $1.90(1.81,1.99)$ \\
\hline & $3 r d$ & $1.69(1.59,1.79)$ & $1.89(1.80,1.98)$ \\
\hline & 4 th & $1.72(1.61,1.82)$ & $1.78(1.69,1.87)$ \\
\hline & $p$-value & 0.12 & 0.01 \\
\hline & continuous ( $p$-value) & $-0.03(0.07)$ & $-0.06(<0.01)$ \\
\hline \multirow[t]{6}{*}{ Family Structure } & 1st (least favorable) & $1.88(1.81,1.96)$ & $2.00(1.94,2.05)$ \\
\hline & 2nd & $1.76(1.66,1.87)$ & $1.89(1.80,1.98)$ \\
\hline & $3 r d$ & $1.75(1.65,1.86)$ & $1.84(1.76,1.93)$ \\
\hline & 4 th & $1.61(1.50,1.71)$ & $1.76(1.67,1.84)$ \\
\hline & $p$-value & $<0.01$ & $<0.01$ \\
\hline & continuous (p-value) & $-0.12(<0.01)$ & $-0.10(<0.01)$ \\
\hline
\end{tabular}

a Continuous $p$-value from OLS regression; $p$-value for quartiles a test for trend.

3105 men and women living in Chicago. The majority of social support variables were associated with lower levels of depressive symptoms in women, while the majority of neighborhood stressors were associated with higher levels of depressive symptoms in men and women. A summary measure of neighborhood stressors remained associated with higher depressive symptoms in both men and women after controlling for neighborhood social support. Neighborhood social support remained associated with lower depressive symptoms after adjustment for neighborhood stressors for women but not men. Associations between perceived violence and disorder and depressive symptoms were stronger for individual-level measures than for the measures aggregated at the neighborhood cluster level.

This work built on previous studies by looking at both neighborhood stressors and social support variables separately and simultaneously and examining whether associations differed by gender. Each type of neighborhood measure we used (SSO, 
Table 3

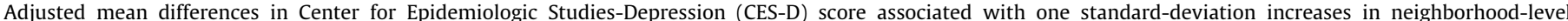
characteristics $(n=3105)$

\begin{tabular}{|c|c|c|c|c|}
\hline \multirow{2}{*}{$\begin{array}{l}\text { Neighborhood } \\
\text { Characteristic }^{\mathrm{a}}\end{array}$} & \multicolumn{2}{|l|}{ Women } & \multicolumn{2}{|l|}{ Men } \\
\hline & $\begin{array}{l}\text { Adjusted for neighborhood- } \\
\text { level characteristics only }\end{array}$ & $\begin{array}{l}\text { +individual-level } \\
\text { characteristics }^{\mathrm{b}}\end{array}$ & $\begin{array}{l}\text { Adjusted for neighborhood- } \\
\text { level characteristics only }\end{array}$ & $\begin{array}{l}\text { + individual-level } \\
\text { characteristics }^{\mathrm{b}}\end{array}$ \\
\hline \multicolumn{5}{|l|}{ STRESSORS } \\
\hline Physical Disorder (SSO) & $0.08(0.05,0.12)^{\mathrm{c}}$ & $0.03(0.00,0.07)$ & $0.04(0.00,0.09)^{\mathrm{c}}$ & $0.02(-0.02,0.06)$ \\
\hline Physical Decay (SSO) & $0.05(0.02,0.09)^{\mathrm{c}}$ & $-0.01(-0.04,0.03)$ & $0.05(0.00,0.09)^{c}$ & $0.01(-0.03,0.06)$ \\
\hline Perceived Violence & $0.09(0.06,0.13)^{c}$ & $0.04(0.01,0.07)^{\mathrm{c}}$ & $0.08(0.04,0.12)^{\mathrm{c}}$ & $0.05(0.01,0.08)^{\mathrm{c}}$ \\
\hline Perceived Disorder & $0.10(0.07,0.13)^{\mathrm{c}}$ & $0.04(0.00,0.07)$ & $0.07(0.04,0.11)^{\mathrm{c}}$ & $0.04(0.00,0.08)^{c}$ \\
\hline \multicolumn{5}{|l|}{ SOCIAL SUPPORT } \\
\hline Social Cohesion & $-0.09(-0.12,-0.06)^{\mathrm{c}}$ & $-0.05(-0.08,-0.02)^{\mathrm{c}}$ & $-0.06(-0.10,-0.02)^{\mathrm{c}}$ & $-0.03(-0.07,0.00)$ \\
\hline Reciprocal Exchange & $-0.05(-0.08,-0.02)^{\mathrm{c}}$ & $-0.03(-0.06,0.00)^{\mathrm{c}}$ & $-0.03(-0.06,0.01)$ & $-0.02(-0.05,0.01)$ \\
\hline Social Ties & $-0.02(-0.05,0.01)$ & $-0.02(-0.05,0.01)$ & $-0.01(-0.04,0.03)$ & $0.00(-0.03,0.04)$ \\
\hline Residential Stability & $-0.05(-0.09,-0.02)^{c}$ & $-0.05(-0.08,-0.02)^{\mathrm{c}}$ & $-0.04(-0.08,0.00)^{c}$ & $-0.03(-0.06,0.01)$ \\
\hline Family Structure & $-0.10(-0.13,-0.07)^{\mathrm{c}}$ & $-0.06(-0.10,-0.02)^{\mathrm{c}}$ & $-0.13(-0.17,-0.08)^{c}$ & $-0.08(-0.13,-0.03)^{c}$ \\
\hline \multicolumn{5}{|l|}{ FACTOR SCORES } \\
\hline Stressors Factor ${ }^{d}$ & $0.10(0.07,0.14)^{c}$ & $0.04(0.00,0.08)^{c}$ & $0.08(0.04,0.12)^{c}$ & $0.04(0.00,0.09)$ \\
\hline Social Support Factor ${ }^{d}$ & $-0.06(-0.10,-0.02)^{\mathrm{c}}$ & $-0.05(-0.09,-0.01)^{\mathrm{c}}$ & $-0.03(-0.07,0.01)$ & $-0.02(-0.02,0.06)$ \\
\hline
\end{tabular}

${ }^{a}$ All neighborhood variables are in $z$-score units (per 1 SD increase). Models include only one neighborhood variable (separate models for each neighborhood-level variable).

${ }^{\mathrm{b}}$ Individual level variables $=$ marital status, age, education, income, race/ethnicity

${ }^{c} p \leq 0.05$

d Social support factor and stressors factor included in model simultaneously

Table 4

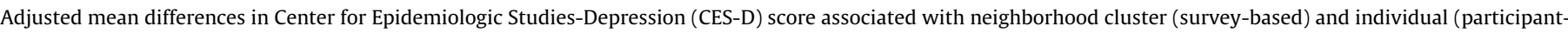
reported) level characteristics $(n=3105)$.

\begin{tabular}{|c|c|c|c|}
\hline Variable & Level & Women & Men \\
\hline Perceived Violence & $\begin{array}{l}\text { Neighborhood Cluster (NC) } \\
\text { Individual } \\
\text { NC, adjusted for individual } \\
\text { Individual, adjusted for NC }\end{array}$ & $\begin{array}{c}0.04(0.01,0.07)^{\mathrm{a}} \\
0.09(0.05,0.13)^{\mathrm{a}} \\
-0.01(-0.05,0.03) \\
0.09(0.05,0.13)^{\mathrm{a}}\end{array}$ & $\begin{array}{c}0.05(0.01,0.08)^{\mathrm{a}} \\
0.12(0.08,0.16)^{\mathrm{a}} \\
-0.02(-0.06,0.03) \\
0.13(0.08,0.17)\end{array}$ \\
\hline Perceived Disorder & $\begin{array}{l}\mathrm{NC} \\
\text { Individual } \\
\mathrm{NC} \text {, adjusted for individual } \\
\text { Individual, adjusted for NC }\end{array}$ & $\begin{array}{c}0.04(0.00,0.07) \\
0.08(0.05,0.13)^{\mathrm{a}} \\
-0.03(-0.08,0.02) \\
0.09(0.05,0.13)^{\mathrm{a}}\end{array}$ & $\begin{array}{c}0.04(0.00,0.08)^{\mathrm{a}} \\
0.10(0.06,0.14)^{\mathrm{a}} \\
-0.02(-0.07,0.02) \\
0.11(0.06,0.16)^{\mathrm{a}}\end{array}$ \\
\hline Social Cohesion & $\begin{array}{l}\mathrm{NC} \\
\text { Individual } \\
\mathrm{NC} \text {, adjusted for individual } \\
\text { Individual, adjusted for NC }\end{array}$ & $\begin{array}{l}-0.05(-0.08,-0.02)^{\mathrm{a}} \\
-0.05(-0.09,-0.02)^{\mathrm{a}} \\
-0.03(-0.07,0.00) \\
-0.04(-0.08,0.00)^{\mathrm{a}}\end{array}$ & $\begin{array}{l}-0.03(-0.07,0.00) \\
-0.08(-0.12,-0.04)^{\mathrm{a}} \\
0.001(-0.04,0.04)^{\mathrm{a}} \\
-0.08(-0.12,-0.04)^{\mathrm{a}}\end{array}$ \\
\hline Reciprocal Exchange & $\begin{array}{l}\mathrm{NC} \\
\text { Individual } \\
\mathrm{NC} \text {, adjusted for individual } \\
\text { Individual, adjusted for NC }\end{array}$ & $\begin{array}{l}-0.03(-0.06,0.00)^{\mathrm{a}} \\
-0.03(-0.06,0.00) \\
-0.02(-0.06,0.01) \\
-0.02(-0.05,0.02)\end{array}$ & $\begin{array}{l}-0.02(-0.05,0.01) \\
-0.02(-0.05,0.02) \\
-0.01(-0.05,0.02) \\
-0.01(-0.05,0.03)\end{array}$ \\
\hline Social Ties & $\begin{array}{l}\mathrm{NC} \\
\text { Individual } \\
\mathrm{NC} \text {, adjusted for individual } \\
\text { Individual, adjusted for NC }\end{array}$ & $\begin{array}{r}-0.02(-0.05,0.01) \\
-0.01(-0.03,0.02) \\
-0.02(-0.06,0.01) \\
0.00(-0.03,0.03)\end{array}$ & $\begin{array}{c}0.00(-0.03,0.04) \\
-0.04(-0.08,0.00)^{\mathrm{a}} \\
0.02(-0.01,0.06) \\
-0.05(-0.09,-0.01)^{\mathrm{a}}\end{array}$ \\
\hline
\end{tabular}

${ }^{\mathrm{a}} p<0.05$

survey-based, and census-based) has different strengths and limitations. The use of SSO data circumvents the problem of same-source bias, as it is collected by objective raters. Census-based survey measures also avoid same-source bias, but may be more indirect, upstream indicators of neighborhood support and stress. Survey-based measures can measure properties of neighborhoods that cannot be observed by raters, such as the presence of social cohesion.

Similar to the results from this study, perceptions of neighborhood environments as stressful (unsafe, violent, and highly disordered) have been found to be associated with higher depressive symptoms in prior work (Christie-Mizell et al., 2003;
Yen et al., 2006; Hadley-Ives et al., 2000; Latkin and Curry, 2003). Our study measured four neighborhood-level stressors using rater assessments of the physical environment and surveys (with responses both aggregated to the neighborhood-cluster level and used for each individual). While many studies have examined associations between depression and residents' perceptions of their neighborhoods as disordered or violent (Christie-Mizell et al., 2003; Dupere and Perkins, 2007; Gary et al., 2007; HadleyIves et al., 2000; Latkin and Curry, 2003; Mulvaney and Kendrick, 2005; Ross, 2000a, Ross and Jang, 2000; Schieman and Meersman, 2004; Schulz et al., 2006; Simons et al., 2002; Steptoe and Feldman, 2001; Yen et al., 2006), very few have measured the 
physical environment through objective raters (Natsuaki et al., 2007; Simons et al., 2002) or aggregated survey responses to the neighborhood level (Simons et al., 2002) and compared results between individual reports of neighborhood stressors and aggregated neighborhood responses. The robustness of our results to different measures supports a possible causal effect of neighborhood environments on depression. We also found that when we simultaneously controlled for individual-level and neighborhood cluster-level perceived violence and disorder, only the individual-level measure remained associated with depressive symptoms. Many of these survey-based measures must operate through individual-level perceptions, so it is not surprising that the "neighborhood" effects disappear when the more proximally measured perception is included in the model. The results from our study provide support for the hypothesis that neighborhood stressors operate through individuals' perceptions of their environments.

Other work has also shown that greater social cohesion and higher levels of exchange of help and information between neighbors are associated with lower levels of depressive symptoms (Aneshensel and Sucoff, 1996; Finfgeld-Connett, 2005). Eleven of twelve studies we found that measured individuals' perceptions of neighborhood social cohesion, social capital, social support, informal social ties, and/or knowing one's neighbors concluded that higher levels of perceived neighborhood social support were associated with lower levels of depression/depressive symptoms (Aneshensel and Sucoff, 1996; Caughy et al., 2003; Fitzpatrick et al., 2005; Gary et al., 2007; Gutman and Sameroff, 2004; la Gory and Fitpatrick, 1992; Latkin and Curry, 2003; Mulvaney and Kendrick, 2005; Schulz et al., 2006; Steptoe and Feldman, 2001; Stevenson, 1998; Ross et al., 2000b). In contrast, we found only four studies that aggregated individuals' neighborhood perceptions to the neighborhood level (Dupere and Perkins, 2007; Cutrona et al., 2000; Simons et al., 2002; Mair et al., 2009), and only one of these found significant associations between depression and neighborhood social conditions. Our results indicated that the neighborhood- and individual-level survey measures of neighborhood social support had associations with depressive symptoms of a similar magnitude (with the exception of social ties and cohesion amongst men, where the individuallevel reports had stronger associations), and that the association of the neighborhood measure with depressive symptoms did not change as much after adjustment for the individual level analogue. Since the majority of studies linking neighborhood social support to depression are based on individuals' self-reports of their neighborhood environment, our study reports some of the first evidence that the neighborhood social environment is related to depressive symptoms independent of perceptions of social connections. The mechanisms underlying these associations need to be further investigated.

Few studies have simultaneously examined neighborhood stressors and social support variables. Of those that have, one study (Steptoe and Feldman, 2001) found that neighborhood problems were associated with higher levels of depression, independent of social cohesion and social capital (which were not associated with lower levels of depression). Similarly, another study (Mulvaney and Kendrick, 2005) of mothers of young children found that neighborhood social capital was no longer associated with lower levels of depressive symptoms after adjusting for self-reported stress. When we simultaneously examined factors representing stressors and social support, we found the same qualitative results as when we looked at individual stressors and support variables unadjusted for one another. In men and women, a summary measure of stressors remained associated with depressive symptoms after adjustment for social support; and in women social support remained associated with lower levels of depressive symptoms after adjustment for stressors. Our results therefore show that both constructs may operate independently of each other.

Our results also document interesting gender differences in the strength of associations between neighborhood characteristics and depressive symptoms, although this heterogeneity was not statistically significant. In models controlling for individual-level covariates, four of five social support variables were associated with lower levels of depressive symptoms in women. The only statistically significant social support measure for men was family structure, a measure of the percentage of female-headed households with children and the proportion of married people aged 15 and over. Social support may have stronger effects among women, as they tend to have better connections with others and are better able to utilize formal and informal social structures (Schuster et al., 1990). Previous studies that have examined the heterogeneity of effects for men and women have been inconsistent: some have found no difference between genders (Wainwright and Surtees, 2004; Matheson et al., 2006), while others have found associations between neighborhood conditions and depression to differ between men and women. Specifically, neighborhood problems and cohesiveness were more strongly associated with depression in women than men (Gutman and Sameroff, 2004), social capital and depression were more strongly associated in teenage women than men (Fitzpatrick et al., 2005), neighborhood violence, cohesion, and aesthetic quality had a stronger association with depressive symptoms in women than men (Mair et al., 2009), and neighborhood walkability was associated with depression amongst men but not women (Berke et al., 2007). The inconsistency between studies is likely due to the different types of neighborhood features being investigated and the age range of the studies' participants. Our study investigated a wide range of neighborhood features and found consistently stronger associations of neighborhood social support measures in women than in men. Gender differences in neighborhood effects on depression need to be confirmed in other studies and investigated further.

There are several limitations to this study. Although the sample size (3105 participants) was large, it was potentially not large enough to have the power to detect cross-level interactions. For example, we found no statistically significant interactions between neighborhood characteristics and gender, although inspection of patterns suggested important differences. Women and African Americans were oversampled, but a post-stratification weight was used in order to make the age, sex, and racial/ ethnic composition match the city of Chicago circa 2003. All analyses were cross-sectional, leaving results open to the possibility of reverse causation and residual confounding by individual-level variables. Reverse causation would arise if people who are depressed tend to stay in or move into deprived neighborhoods. In this case the exposure to the neighborhood condition is a consequence of (and not a cause of) depression. Longitudinal designs are necessary to rule out reverse causation as an explanation for cross-sectional associations. The crosssectional nature also did not allow us to investigate the most relevant time frame. If neighborhood features operate over the course of years, or decades, to alter mental health, cross-sectional associations may underestimate long-term effects. Neighborhood clusters were used to represent neighborhoods. These neighborhoods were carefully constructed, and likely represent "true" neighborhoods, but these boundaries may not be the most relevant to the development of depressive symptoms. Block groups or other, smaller, neighborhood definitions could not be used in this analysis, as there were only one or two residents in many of the block groups, as compared to a mean of nine subjects in neighborhood clusters, so that the survey-based measures would be averaged over very few participants. Similarly, there 
were many fewer streets per block group than per neighborhood cluster rated in the SSO data, a potential problem when creating accurate measures of physical disorder and decay. We did not investigate other potentially important neighborhood conditions that may be associated with depressive symptoms, such as race/ethnic density and urbanicity. Participation rates were high (72\%) for random population samples in a large US city. Weights were used to partly account for differential participation. If nonparticipation was simultaneously linked to both depressive symptoms and adverse neighborhood environments our results may underestimate true associations of neighborhood context with depression.

While it may seem that the size of the associations between neighborhood environments and depressive symptoms in this study were fairly small, they are similar in magnitude to those between important individual-level predictors and depressive symptoms. For example, the mean difference in depressive symptoms for a woman with $<12$ years of education vs. $16+$ years is 0.07 ; the mean difference in depressive symptoms comparing married to divorced individuals are 0.12 and 0.30 in men and women, respectively. When compared to coefficients as large as 0.12 for perceived violence in men, it becomes clear that the magnitudes of the associations of neighborhood factors with depressive symptoms are comparable to those observed for other risk factors.

\section{Table A1}

Neighborhood scale scores from the CCAHS community survey.

\begin{tabular}{|c|c|}
\hline $\begin{array}{l}\text { Perceived } \\
\text { Disorder }\end{array}$ & $\begin{array}{l}\text { 1. How much trash or broken glass on sidewalks and streets } \\
\text { do you see in your neighborhood? } \\
\text { 2. How much graffiti do you see on buildings and walls in } \\
\text { your neighborhood? } \\
3 \text {. How many vacant or deserted houses or storefronts do } \\
\text { you see in your neighborhood? } \\
\text { 4. How often do you see people drinking in public places in } \\
\text { your neighborhood? } \\
5 \text {. How often do you see unsupervised children hanging out } \\
\text { in the street in your neighborhood? }\end{array}$ \\
\hline $\begin{array}{l}\text { Perceived } \\
\text { Violence }\end{array}$ & $\begin{array}{l}\text { During the past six months, how often: } \\
\text { 1. was there a fight in your neighborhood in which a } \\
\text { weapon was used? } \\
\text { 2. was there a violent argument between neighbors? } \\
\text { 3. were there gang fights in your neighborhood? } \\
\text { 4. was there a sexual assault or rape in your neighborhood? } \\
\text { 5. was there a robbery or mugging in your neighborhood? }\end{array}$ \\
\hline Social Cohesion & $\begin{array}{l}\text { 1. People around here are willing to help their neighbors } \\
\text { 2. People in this neighborhood generally get along with } \\
\text { each other } \\
\text { 3. People in this neighborhood can be trusted } \\
\text { 4. People in this neighborhood share the same values } \\
\text { 5. This is a close-knit neighborhood }\end{array}$ \\
\hline $\begin{array}{l}\text { Reciprocal } \\
\text { Exchange }\end{array}$ & $\begin{array}{l}\text { 1. About how often do you and people in your neighborhood } \\
\text { do favors for each other? By favors we mean such things as } \\
\text { watching each other's children, helping with shopping, } \\
\text { lending garden or house tools, and other small acts of } \\
\text { kindness. } \\
\text { 2.When a neighbor is not at home or on vacation, how often } \\
\text { do you and other neighbors watch over their property? } \\
\text { 3. How often do you and other people in the neighborhood } \\
\text { ask each other advice about personal things such as child } \\
\text { rearing or job openings? } \\
\text { 4. How often do you and people in this neighborhood have } \\
\text { parties or other get-togethers where other people in the } \\
\text { neighborhood are invited? } \\
5 \text {. How often do you and other people in this neighborhood } \\
\text { visit in each other's homes or on the street? }\end{array}$ \\
\hline $\begin{array}{l}\text { Number of } \\
\text { Social Ties }\end{array}$ & $\begin{array}{l}\text { 1. Not counting those who live with you, how many of your } \\
\text { relatives or in-laws live in your neighborhood? } \\
2 \text {. How many friends do you have who live in your } \\
\text { neighborhood? }\end{array}$ \\
\hline
\end{tabular}

These findings indicate that neighborhood environments play an important role for both men and women in shaping their mental health. Recent experimental evidence from the Moving to Opportunity study found that adults (mostly women) moving from poor to non-poor neighborhoods reported lower levels of distress and depressive symptoms than those who remained in poor neighborhoods (Leventhal and Brooks-Gunn, 2003; Kling et al., 2007). Our results are consistent with these findings. Results from observational studies need to be confirmed in experimental or quasi-experimental designs. Nevertheless, taken together with prior work, our results suggest that reducing the presence of violence and disorder in neighborhoods and/or working to create social support systems may help improve mental health.

\section{Appendix}

See Table A1.

\section{References}

Aneshensel, C.S., Sucoff, C.A., 1996. The neighborhood context of adolescent mental health. J. Health Soc. Behav. 37, 293-310.

Berke, E.M., Gottlieb, L.M., Moudon, A.V., Larson, E.B., 2007. Protective association between neighborhood walkability and depression in older men. J. Am. Geriatr. Soc. 55, 526-533.

Carpenter, J.S., Andrykowski, M.A., Wilson, J., Hall, L.A., Rayens, M.K., Sachs, B., Cunningham, L.L., 1998. Psychometrics for two short forms of the Center for Epidemiologic Studies-Depression Scale. Issues Ment. Health Nurs. 19, 481-494.

Caughy, M.O., O'Campo, P.J., Muntaner, C., 2003. When being alone might be better: neighborhood poverty, social capital, and child mental health. Soc. Sci. Med. 57, 227-237.

Christie-Mizell, C.A., Steelman, L.C., Stewart, J., 2003. Seeing their surroundings: the effects of neighborhood setting and race on maternal distress. Soc. Sci. Res. $32,402-428$.

Cutrona, C.E., Russell, D.W., Hessling, R.M., Brown, P.A., Murry, V., 2000. Direct and moderating effects of community context on the psychological well-being of African American women. J. Pers. Soc. Psychol. 79, 1088-1101.

Dupere, V., Perkins, D.D., 2007. Community types and mental health: a multilevel study of local environmental stress and coping. Am. J. Commun. Psychol. 39 107-119.

Everson-Rose, S.A., House, J.S., Mero, R.P., 2004. Depressive symptoms and mortality risk in a national sample: confounding effects of health status. Psychosom. Med. 66, 823-830.

Finfgeld-Connett, D., 2005. Clarification of social support. J. Nurs. Scholarship 37 4-9.

Fitzpatrick, K.M., Piko, B.F., Wright, D.R., Lagory, M., 2005. Depressive symptomatology, exposure to violence, and the role of social capital among African American adolescents. Am. J. Orthopsychiatry 75, 262-274.

Gary, T.L., Stark, S.A., Laveist, T.A., 2007. Neighborhood characteristics and mental health among African Americans and whites living in a racially integrated urban community. Health Place 13, 569-575.

Groenewegen, P.P., Van den Berg, A.E., de Vries, S., Verheij, R.A., 2006. Vitamin G: effects of green space on health, well-being, and social safety. BMC Public Health 6, 149.

Gutman, L.M., Sameroff, A.J., 2004. Continuities in depression from adolescence to young adulthood: contrasting ecological influences. Dev. Psychopathol. 16 967-984.

Hadley-Ives, E., Stiffman, A.R., Elze, D., Johnson, S.D., Dore, P., 2000. Measuring Neighborhood and school environments: perceptual and aggregate approaches. J.Hum. Behav. Soc. Environ. 3, 1-28.

Kling, J.R., Liebman, J.B., Katz, L.F., 2007. Experimental analysis of neighborhood effects. Econometrica 75, 83-119.

Kohout, F.J., Berkman, L.F., Evans, D.A., Cornoni-Huntley, J., 1993. Two shorter forms of the CES-D (Center for Epidemiological Studies Depression) depression symptoms index. J. Aging Health 5, 179-193.

Kruger, D.J., Reischl, T.M., Gee, G.C., 2007. Neighborhood social conditions mediate the association between physical deterioration and mental health. Am. J. Commun. Psychol. 40, 261-271.

Kubzansky, L.D., Subramanian, S.V., Kawachi, I., Fay, M.E., Soobader, M.J., Berkman L.F., 2005. Neighborhood contextual influences on depressive symptoms in the elderly. Am. J. Epidemiol. 162, 253-260.

La Gory, M., Fitpatrick, K., 1992. The effects of environmental context on elderly depression. J. Aging Health 4, 459-479.

Latkin, C.A., Curry, A.D., 2003. Stressful neighborhoods and depression: a prospective study of the impact of neighborhood disorder. J. Health Soc. Behav. 44, 34-44. 
Leventhal, T., Brooks-Gunn, J., 2003. Moving to opportunity: an experimental study of neighborhood effects on mental health. Am. J. Public Health 93, 1576-1582.

Lewis, D.A., Maxfield, M.G., 1980. Fear in the neighborhoods: An investigation of the impact of crime. J. Res. Crime Delinquincy 17, 160-189.

Mair, C., Diez Roux, A.V., Shen, M., Shea, S., Seeman, T., Echeverria, S., O'meara, E.S., 2009. Cross-sectional and longitudinal associations of neighborhood cohesion and stressors with depressive symptoms in the multiethnic study of atherosclerosis. Ann. Epidemiol. 19, 49-57.

Mair, C., Roux, A.V., Galea, S., 2008. Are neighbourhood characteristics associated with depressive symptoms? A review of evidence. J. Epidemiol. Commun. Health 62, 940-946 8 p following 946. .

Matheson, F.I., Moineddin, R., Dunn, J.R., Creatore, M.I., Gozdyra, P., Glazier, R.H., 2006. Urban neighborhoods, chronic stress, gender and depression. Soc. Sci. Med. 63, 2604-2616.

Morenoff, J.D., 2003. Neighborhood mechanisms and the spatial dynamics of birth weight. Ajs 108, 976-1017.

Morenoff, J.D., House, J.S., Hansen, B.B., Williams, D.R., Kaplan, G.A., Hunte, H.E., 2007. Understanding social disparities in hypertension prevalence, awareness, treatment, and control: the role of neighborhood context. Soc. Sci. Med. 65, 1853-1866.

Mujahid, M.S., Diez Roux, A.V., Morenoff, J.D., Raghunathan, T., 2007. Assessing the measurement properties of neighborhood scales: from psychometrics to ecometrics. Am. J. Epidemiol. 165, 858-867.

Mulvaney, C., Kendrick, D., 2005. Depressive symptoms in mothers of pre-school children-effects of deprivation, social support, stress and neighbourhood social capital. Soc. Psychiatry Psychiatr. Epidemiol. 40, 202-208.

Natsuaki, M.N., Ge, X., Brody, G.H., Simons, R.L., Gibbons, F.X., Cutrona, C.E., 2007. African American children's depressive symptoms: the prospective effects of neighborhood disorder, stressful life events, and parenting. Am. J. Commun. Psychol.

Perkins, D.D., Taylor, R.B., 1996. Ecological assessments of community disorder: their relationship to fear of crime and theoretical implications. Am. J. Commun. Psychol. 24, 63-107.

Radloff, L., 1977. The CES-D scale: a self-report depression scale for research in the general population. Appl. Psychol. Meas. 1, 385-401.

Ross, C., 2000a. Neighborhood disadvantage and adult depression. J. Health Soc. Behav. 41, 177-187.

Ross, C., Reynolds, J.R., Geis, K.J., 2000b. The contingent meaning of neighborhood stability for residents' psychological well-being. Am. Sociological Rev. 65, 581-597.
Ross, C.E., Jang, S.J., 2000. Neighborhood disorder, fear, and mistrust: the buffering role of social ties with neighbors. Am. J. Commun. Psychol. 28, 401-420.

Sampson, R.J., 1987. Urban black violence: the effect of male joblessness and family disruption. Am. J. Sociol. 93, 348-382.

Sampson, R.J., Morenoff, J., Raudenbush, S.W., Swaroop, S., 2007. Ecometrics: the use of surveys and observational methods to study social settings. In: Wikstrom, P.O. (Ed.), Social Contexts of Pathways in Crime: Methods and Analytic Techniques.. Cambridge University Press, Cambridge, UK.

Sampson, R.J., Morenoff, J.D., Earls, F., 1999. Beyond social capital: spatial dynamics of collective efficacy for children. Am. Sociological Rev. 64, 633-660.

Sampson, R.J., Raudenbush, S.W., 1999. Systematic social observation of public spaces: a new look at disorder in urban neighborhoods. Am. J. Sociol. 105, 603-651.

Sampson, R.J., Raudenbush, S.W., Earls, F., 1997. Neighborhoods and violent crime: a multilevel study of collective efficacy. Science 277, 918-924.

Schieman, S., Meersman, S.C., 2004. Neighborhood problems and health among older adults: received and donated social support and the sense of mastery as effect modifiers. J. Gerontol. B Psychol. Sci. Soc. Sci. 59, S89-S97.

Schulz, A.J., Israel, B.A., Zenk, S.N., Parker, E.A., Lichtenstein, R., Shellman-Weir, S., Klem, A.B., 2006. Psychosocial stress and social support as mediators of relationships between income, length of residence and depressive symptoms among African American women on Detroit's eastside. Soc. Sci. Med. 62, 510-522.

Schuster, T.L., Kessler, R.C., Aseltine Jr, R.H., 1990. Supportive interactions, negative interactions, and depressed mood. Am. J. Commun. Psychol. 18, 423-438.

Simons, R.L., Murry, V., Mcloyd, V., Lin, K.H., Cutrona, C., Conger, R.D., 2002. Discrimination, crime, ethnic identity, and parenting as correlates of depressive symptoms among African American children: a multilevel analysis. Dev. Psychopathol. 14, 371-393.

Steptoe, A., Feldman, P.J., 2001. Neighborhood problems as sources of chronic stress: development of a measure of neighborhood problems, and associations with socioeconomic status and health. Ann. Behav. Med. 23, 177-185.

Stevenson, H.C., 1998. Raising safe villages: Cultural-ecological factors that influence the emotional adjustment of adolescents. J. Black Psychol. 24, 44-59.

Wainwright, N.W., Surtees, P.G., 2004. Places, people, and their physical and mental functional health. J. Epidemiol. Commun. Health 58, 333-339.

Yen, I.H., Yelin, E.H., Katz, P., Eisner, M.D., Blanc, P.D., 2006. Perceived neighborhood problems and quality of life, physical functioning, and depressive symptoms among adults with asthma. Am. J. Public Health 96 (873-9). 